\title{
Automation of data-driven rate equation screening for heterogeneously-catalyzed reactions
}

\author{
Vasco Saltão ${ }^{1}$, Joris Thybaut ${ }^{2}$, Laura Pirro ${ }^{2}$, Filipe Freire $^{1}$, and Pedro Mendes ${ }^{2}$ \\ ${ }^{1}$ Universidade de Lisboa Departamento de Engenharia Quimica \\ ${ }^{2}$ Ghent University
}

March 2, 2022

\begin{abstract}
Automating the generation of suitable kinetic models could dramatically improve its application to novel reactions. Therefore, a software tool was developed to automatically propose rate equations for a catalytic reaction, purely based on experimental data. The tool screens theoretical initial rate equations by comparing the trends predicted by theoretical equations (from a comprehensive library) with those present in the experimental data, thus eliminating the rate equations that cannot reproduce the trends in the data. Afterwards, the kinetic models associated to the feasible rate equations are ranked based on trend similarity, resulting in an ordered list of models ready for regression. For most of the tested literature datasets, the tool proposed the same rate equation as experienced researchers. This is a key first step into the automation of kinetic modelling that, once generalized, will allow to its widespread use in the understanding of catalytic reactions.
\end{abstract}

\section{Hosted file}

Salt \selectlanguage\{ngerman\}ão et al_AIChEJ2022_Manuscript.docx available at https: //authorea.com/users/463259/articles/558401-automation-of-data-driven-rate-equationscreening-for-heterogeneously-catalyzed-reactions 